\title{
Reconfigurações da docência universitária: um olhar focado no Processo de Bolonha
}

\section{Higher education teaching reconfiguration: a focused view on the Bologna Process}

\author{
Carlinda Leite ${ }^{1}$ \\ Kátia Ramos ${ }^{2}$
}

\begin{abstract}
RESUMO
O Processo de Bolonha, legislado em Portugal em 2006, através do Decreto-Lei n ${ }^{0}$ 74/2006 (PORTUGAL, 2006), anunciou a intenção de romper com o tradicional exercício da docência, focado na transmissão e reprodução dos conhecimentos existentes, e veiculou um modelo de formação centrado na aprendizagem dos estudantes. Este Processo implicou uma reorganização dos currículos do ensino universitário e exigiu uma reconfiguração do exercício da docência apoiada em uma nova concepção do papel e do trabalho dos estudantes. É no quadro desta problemática que se situa este artigo, que tem como objetivo dar a conhecer efeitos na docência universitária decorrentes do Processo de Bolonha. Para isso, o artigo, depois de caracterizar medidas políticas decorrentes do compromisso de Bolonha, analisa dados recolhidos de professores da Universidade do Porto sobre a relação entre as alterações previstas no ideário político e as condições para a sua concretização.
\end{abstract}

Palavras-chave: docência universitária; Processo de Bolonha; reorganização curricular.

\section{DOI: $10.1590 / 0104-4060.42038$}

1 Universidade do Porto. Porto, Portugal. Pça. De Gomes Teixeira, 4099-002. (Faculdade de Psicologia e de Ciências da Educação da Universidade do Porto, Rua Alfredo Allen, 4300-135, Porto, Portugal).E-mail: carlinda@fpce.up.pt

2 Centro de Educação da Universidade Federal de Pernambuco. Recife, Pernambuco, Brasil. Avenida Acadêmico Hélio Ramos, Cidade Universitária, s/n. CEP: 50.670-901. E-mail: katiamcramos@gmail.com 


\begin{abstract}
The Bologna Process (Processo de Bolonha) was legislated in Portugal in 2006 through the Decree $n^{\circ} 74 / 2006$ (PORTUGAL, 2006). This Law announced the need to change the traditional teaching method which focused on knowledge transfer to a method centred on student learning. This Process demanded a higher education curricular organization and a teaching reconfiguration supported on a new conception of the students' work and roles. This article is based on the problem mentioned above which highlights the impact that the Bologna Process had on teaching methods and professors' workload. For that reason, after characterizing political measures resulting from the Bologna Process, the article analyses data collected from the Porto University professors about the relationship between the proposed changes and the conditions for their concretization.
\end{abstract}

Keywords: university teaching; Bologna process; curricular reorganization.

\title{
Introdução
}

O início deste século XXI vem sendo marcado pela anunciação e materialização de propostas que, gestadas na esteira da crítica ao modelo de racionalidade baseado na neutralidade científica (BERNSTEIN, 1997) e na compreensão da natureza compósita do conhecimento (GIBBONS et al., 1998; SANTOS, 1996; MAGALHÃES, 2004), colocaram o terceiro milênio como pretenso palco de concretização da superação de dicotomias que inviabilizam uma comunicação entre culturas e destas com o mundo do trabalho - principalmente no sentido apontado por Santos (1996), de superação das dicotomias "alta cultura-cultura popular", "educação-trabalho" e "teoria-prática".

Nesse quadro, a Declaração Mundial sobre a Educação Superior no Século XXI: visão e ação (UNESCO, 1998, não paginado) colocou o Ensino Superior (ES) na ordem do dia, ao afirmar que "[...] há uma demanda sem precedentes e uma grande diversificação na educação superior, bem como maior consciência sobre a sua importância vital tanto para o desenvolvimento sociocultural e econômico como para a construção do futuro".

Em sintonia com essa Declaração, e fiel aos propósitos de fortalecer os países pertencentes à União Europeia, a assinatura da Declaração de Bolonha, em junho de 1999, desencadeou o denominado Processo de Bolonha (PB) que, tendo como principal objetivo a promoção da empregabilidade e competitividade internacional do sistema europeu do ES, alterou substancialmente este nível 
de ensino em termos de estrutura, acesso e atenção ao processo de ensino, que passou a assumir como central a aprendizagem dos estudantes. (DECLARAÇÃO DE BOLONHA, 1999).

Em Portugal, o PB tem amparo legal no Decreto-Lei n ${ }^{\circ} 74 / 2006$ (PORTUGAL, 2006), que regulamenta as alterações relativas ao modelo organizacional do ES de adequação a este Processo. Dessas alterações, no TÍTULO IV, Adequação dos Ciclos de Estudo, é explicitada a necessidade de "[...] adequação das formações ao novo modelo de organização do ensino superior" (PORTUGAL, 2006, p. 2243), que passa a ser estruturado em três níveis: $1^{\circ}$ ciclo, de 3 anos, que confere o diploma de graduação; $2^{\circ}$ ciclo, de 2 anos, que corresponde ao mestrado; $3^{\circ}$ ciclo, de 3 anos, para a obtenção do doutorado.

É nesse contexto que a docência é convocada a adequar-se ao novo modelo organizacional, principalmente em termos de uma reconfiguração da relação professor-estudante-conhecimento, isto é, a reconhecer a docência como uma profissão de relações. (TARDIF; LESSARD, 2005). Ao mesmo tempo, os professores são pressionados por um transbordamento de funções (NÓVOA, 2007) que afetam as suas condições de trabalho e que continuam regidas pelo o que Delgado (2007) denomina de capitalismo acadêmico.

É no âmbito dessa problemática que este artigo dá conta de um estudo realizado na Universidade do Porto (U.Porto) que teve como objetivo conhecer efeitos na docência universitária decorrentes do Processo de Bolonha. Para tanto, o texto organiza-se em torno de três eixos: i) caracterização de medidas políticas decorrentes do compromisso de Bolonha, notadamente em termos da reorganização curricular e demandas de reconfiguração da docência; ii) procedimentos metodológicos seguidos na recolha de dados; iii) análise dos dados recolhidos, relativos a opiniões de docentes da Universidade do Porto (U.Porto), no contexto da relação entre alterações previstas no ideário do $\mathrm{PB}$ e as ocorridas.

\section{Situando o Processo de Bolonha}

A Declaração Mundial sobre a Educação Superior no Século XXI: visão e ação (UNESCO, 1998), conforme já mencionado, colocou o ES na ordem do dia. Por outro lado, as diretrizes dela emanadas foram ampliadas por demandas do mercado global. (ROBERTSON; DALE, 2001; ROBERTSON, 2009). Neste contexto, conforme aponta Cabrito (2011, p. 16), “[...] a Declaração de Bolonha explica-se, em muito, por uma questão económica, as exigências do mercado internacional, e não por razões internas aos próprios sistemas educativos”. 
É nesse âmbito que se situam reformas advindas de políticas internacionais concebidas como promotoras de um maior desenvolvimento socioeconómico e cultural. Tecendo comentário sobre esta ideia de promoção de desenvolvimento, Maués (2010) afirma que

[...] nessa lógica de vinculação da educação ao mercado, o papel e as funções das universidades passam a ser questionados e surgem novas propostas que orientam as reformas desse nível de ensino. Nesse contexto, o trabalho docente também é alvo das mudanças e esse profissional passa por uma metamorfose que o distancia das tradicionais funções pelas quais era responsável. (MAUÉS, 2010, p. 142).

É nesse quadro de promoção do desenvolvimento que é concebido o PB cujo ideário implicou: modificações de condições de acesso ao ES; alteração da estrutura organizacional do ES em três ciclos, como já foi referido; alteração do paradigma que concebe o ensino baseado na transmissão de conhecimentos para o alicerçado na aprendizagem e no desenvolvimento de competências; adoção do sistema baseado no reconhecimento do trabalho dos estudantes, através do European Credit Transfer and Accumulation System (ECTS). (PORTUGAL, 2006).

No que se refere à organização dos cursos, o $\mathrm{PB}$ implicou novos processos de desenvolvimento curricular (LEITE, 2012), que, do ponto de vista pedagógico e didático, concebem o estudante como sujeito ativo da aprendizagem. Esta orientação curricular, conforme Leite e Ramos (2012), trouxe exigências aos modos de trabalho pedagógico (LESNE, 1984) dos docentes, principalmente no redimensionamento da relação ensino-aprendizagem-avaliação. A par desta forma de conceber a ação docente, a ampliação do ES de estudantes que até aí dele tinham estado afastados obrigou os professores a lidar com situações de diversidade que se afastam do que é considerado o "cliente ideal". (BECKER, 1952).

Em Portugal, conforme já foi referido, o PB foi instituído pelo Decreto-Lei $n^{\circ} 74 / 2006$, que veiculou o discurso de ruptura com o paradigma centrado no ensino para o recentrar na aprendizagem, nomeadamente explicitando que a

[...] questão central no Processo de Bolonha é o da mudança do paradigma de ensino de um modelo passivo, baseado na aquisição de conhecimentos, para um modelo baseado no desenvolvimento de competências, onde se incluem quer as de natureza genérica - instrumentais, interpessoais e sistémicas - quer as de natureza específica associadas à área de formação, e onde a componente experimental e de projecto desempenham um papel importante. (PORTUGAL, 2006, p. 2243). 
No quadro dessa disposição legal, os professores passaram a conviver com o desafio de desenvolver a docência centrada no estudante, ao mesmo tempo que lhes foram feitas exigências advindas da cultura da produtividade (BIANCHETT; MACHADO, 2009) e da lógica de mercado. (ROBERTSON; DALE, 2001; ROBERTSON, 2009; LIMA, 2012).

O desafio da concretização da docência assente no paradigma da aprendizagem, ao exigir a ruptura com o modelo tradicional de ensino, confrontou muitos dos professores com a dificuldade acrescida de recorrerem a processos pedagógico-didáticos em que os estudantes tenham um papel ativo na aprendizagem. Confrontou-os também com a necessidade de assumirem o papel de tutores desse processo, quando, conforme é afirmado por Leite e Magalhães (2009), as condições para o realizarem oferece limites.

Outro dos aspectos que marca o $\mathrm{PB}$ diz respeito ao número de anos necessários para se obter a graduação. De 4 ou de 5 ou de 6 anos, tal como acontecia no período pré-Bolonha, os cursos de graduação decorrentes deste compromisso europeu passaram a ter a duração de 3 anos. A concretização desta reorganização estrutural, conforme Cabrito (2011, p. 19), aponta também para limites do ideário do $\mathrm{PB}$, cuja lógica "[...] parece ser o de vir a constituir-se num processo de produção de indivíduos imediatamente aproveitáveis pelo mercado, esquecendo a sua função de contribuir para o desenvolvimento pessoal dos cidadãos".

Corroborando esta compreensão, Lima, Azevedo e Catani (2008, p. 15) consideram que as políticas do ES decorrentes do PB constituíram “" [...] uma boa oportunidade para adotar lógicas de redução de encargos por parte do Estado, e não para reforçar as condições de trabalho nas escolas, designadamente em termos pedagógicos". Ou seja, e como neste texto damos conta, esta redução inviabiliza desenvolver o currículo segundo a orientação do ideário que é enunciado no PB. De fato, os professores confrontados com exigências da cultura da produtividade e da lógica do mercado têm dificuldade em concretizar procedimentos curriculares que se afastem de processos de mera instrução e se aproximem de situações que desenvolvam a autonomia. (FREIRE, 1996). Conforme Leite e Fernandes (2011, p. 528), “[...] os estudos revelam que a atribuição de centralidade aos estudantes nos processos de ensino-aprendizagem não é um processo fácil nem tão pouco constitui uma regra nos quotidianos institucionais".

Por isso se compreende que a contextualização dos conteúdos a ensinar e a aprender, através da criação e do desenvolvimento de situações em que os estudantes têm o estatuto de participantes ativos, tutorizados nas suas próprias aprendizagens, constitua um desafio a enfrentar pelos professores no âmbito do PB.

Em síntese, no que se refere ao ideário discursivo do PB, o que caracteriza a sua proposição é a superação da perspetiva tradicional do denominado "racionalismo académico" (LEITE, 2002; PACHECO, 2014), que limita a ação 
dos professores à transmissão de informações e a dos considerados alunos à aquisição de conhecimentos. Esta superação tem vindo a constituir um desafio para os docentes, no seu exercício profissional quotidiano, e justifica o estudo empírico que a seguir é apresentado.

\section{Procedimento metodológico}

Para dar conta do propósito de conhecer efeitos na docência universitária decorrentes do Processo de Bolonha, o estudo recorreu a um questionário on-line, aplicado a docentes da U.Porto. A escolha desta Universidade justifica-se por ser uma das instituições que, na adesão ao PB, delineou uma política interna de atenção e de formação pedagógico-didática que permitisse preparar os professores para os desafios que este paradigma coloca ao exercício da docência. Esta ação, ocorrida em 2005, nas vésperas da adequação ao PB, foi designada por "Ação Piloto de Atualização Pedagógico-Didática" e contou com a participação de um conjunto de professores de várias áreas disciplinares e em diferentes estados da carreira universitária. Foi a estes professores que o questionário foi aplicado.

$\mathrm{Na}$ sua estrutura, o questionário continha três perguntas: uma aberta e duas fechadas. No que diz respeito à pergunta aberta, ela permitiu recolher opiniões dos inquiridos sobre desafios vivenciados na docência, principalmente após a Ação de Formação de Atualização Pedagógico-Didática da U.Porto. Em relação às perguntas fechadas, uma era subdividida em 11 itens e outra em 4 , que permitiram recolher opiniões, em uma escala de 4 níveis (pouco, médio, muito, muitíssimo), relativas a transformações ocorridas no Ensino Superior decorrentes do $\mathrm{PB}$ e ao grau de adesão desses professores às políticas atuais no Ensino Superior.

Os professores que responderam ao questionário, no total de 17, pertencem a 8 das 14 Faculdades da U.Porto e distribuem-se pelas diversas categorias profissionais do Ensino Superior, isto é, ocupam lugares desde Assistente a Professor Catedrático. Quanto à representação por Faculdade, há um maior número de professores da Faculdade de Engenharia (29\%) e da Faculdade de Medicina (17\%), o que se explica por serem as instituições, na Universidade do Porto, com maior número de professores e de estudantes. O tempo de exercício docente na U.Porto varia entre 9 e 39 anos e todos eles já pertenciam a esta universidade antes da adequação ao PB (2006).

O contato com os professores foi feito, em um primeiro momento, pessoalmente, por telefone e via e-mail. Depois da adesão à participação no estudo, 
o questionário foi colocado on-line, sendo de resposta anónima. As respostas às perguntas fechadas foram tratadas por estatística simples e as relativas à pergunta aberta por análise de conteúdo. (VALA, 1989; KRIPPERDORF, 2003).

\section{O que dizem os professores da U.Porto sobre alterações previstas e ocorridas decorrentes do Processo de Bolonha}

Considerando as modificações estruturais propostas pelo PB, os dados inicialmente apresentados são os referentes às opiniões dos professores quanto a transformações ocorridas no Ensino Superior pelo PB, nomeadamente os recolhidos através das perguntas fechadas. Como já foi referido, uma das perguntas fechadas continha 11 aspectos que permitiram conhecer as opiniões dos professores relativas às referidas transformações. A Tabela 1 dá conta da distribuição dessas opiniões, em percentagem e número, na escala entre pouco, médio, muito e muitíssimo.

TABELA 1 - OPINIÕES DOS PROFESSORES SOBRE O NÍVEL DE TRANSFORMAÇÕES OCORRIDAS PELO PROCESSO DE BOLONHA

\begin{tabular}{lcccc}
\hline \multicolumn{1}{c}{ Transformações } & \multicolumn{3}{c}{ Nível } \\
\cline { 2 - 5 } & Pouco & Médio & Muito & Muitíssimo \\
\hline a) Na missão atribuída à Universidade, em geral & $19 \%(3)$ & $31 \%(5)$ & $38 \%(6)$ & $12 \%(2)$ \\
$\begin{array}{l}\text { b) Na organização dos cursos universitários } \\
\text { c) No modo como são organizadas as unidades } \\
\text { curriculares }\end{array}$ & $12 \%(2)$ & $12 \%(2)$ & $44 \%(7)$ & $31 \%(5)$ \\
$\begin{array}{l}\text { d) No modo como organiza as unidades } \\
\text { curriculares em que exerce a docência }\end{array}$ & $12 \%(2)$ & $19 \%(3)$ & $38 \%(6)$ & $31 \%(5)$ \\
$\begin{array}{l}\text { e) No modo como é exercida a docência no ensino } \\
\text { universitário }\end{array}$ & $19 \%(0)$ & $25 \%(4)$ & $38 \%(6)$ & $38 \%(6)$ \\
f) No modo como assegura o ensino-aprendizagem & $6 \%(1)$ & $41 \%(5)$ & $31 \%(5)$ & $19 \%(3)$ \\
g) No papel atribuído aos estudantes universitários & $0 \%(0)$ & $25 \%(4)$ & $50 \%(8)$ & $25 \%(4)$ \\
$\begin{array}{l}\text { h) No modo como avalia as aprendizagens } \\
\text { i) No exercício da investigação }\end{array}$ & $19 \%(3)$ & $25 \%(4)$ & $31 \%(5)$ & $25 \%(4)$ \\
j) Nas atividades de extensão & $44 \%(7)$ & $19 \%(3)$ & $25 \%(4)$ & $12 \%(2)$ \\
k) Na relação entre ensino-investigação-extensão & $31 \%(5)$ & $38 \%(6)$ & $25 \%(4)$ & $6 \%(1)$ \\
\hline
\end{tabular}

FONTE: As autoras (2015).

Uma análise dos dados da Tabela 1 permite constatar ter existido uma concentração no nível "muito" (38\%), seguida do "médio" (31\%), no que se 
refere ao reconhecimento de transformações ocorridas na missão atribuída à Universidade. Embora alguns professores tenham optado pelo nível "pouco" (19\%), também outros afirmaram que as transformações ocorridas pelo PB foram "muitíssimo" (12\%). Ou seja, $81 \%$ dos professores reconhecem a existência de transformações na missão atribuída à Universidade. Concluiu-se, pois, que a maioria destes professores reconhece que o PB gerou transformações institucionais na missão universitária.

No que se refere à organização dos cursos universitários e ao modo como são desenhadas as unidades curriculares, a maioria dos inquiridos (75\%) reconhece terem existido transformações, classificando-as com o nível "muito" (44\%) e "muitíssimo" (25\%). Este dado permite concluir que a adequação ao PB, tal qual determinado pelo Decreto-Lei no 74/2006 (PORTUGAL, 2006), implicou uma nova organização dos cursos universitários. Esta reorganização foi, inclusive, explicitamente sentida por estes professores, nos modos de conceber o plano das unidades curriculares que asseguram, o que confirma o que Leite (2012) sustenta quando afirma que o PB desencadeou uma reforma curricular do ensino universitário.

No que diz respeito à forma como são organizadas as unidades curriculares, segundo as opiniões dos professores a que este estudo se reporta, constata-se que $69 \%$ considera que elas passaram a ser organizadas de modo "muito" (38\%) ou "muitíssimo" (31\%) diferentes. Associada a estas opiniões, está também a que reconhece terem existido transformações no modo como é exercida a docência. Neste caso, nenhum dos professores considerou essas transformações de nível "pouco" e 76\% reconheceram-na como sendo de nível "muito" (38\%) ou muitíssimo (38\%).

Como se pode concluir, estes dados são de grande relevância numa análise dos efeitos gerados pela política decorrente do PB. Tendo sido apresentada em Portugal, e como neste artigo já foi afirmado, na intenção de romper com o paradigma focado no ensino substituindo-o por um paradigma focado na aprendizagem, as opiniões dos professores revelam que o PB gerou efeitos nos processos curriculares, passando a atribuir aos professores e aos estudantes novos papéis. (LEITE; FERNANDES, 2011).

Mas, quando se compara estas respostas com as que se referem ao modo como é exercida a docência e como é assegurado o ensino-aprendizagem e avaliadas as aprendizagens, constata-se que existe uma tensão entre o que é proposto e o que é efetivado, tensão revelada na concentração de $75 \%$ das respostas no nível "médio" (31\%) e "muito" (44\%). Neste caso, apesar dos professores reconhecerem que o PB gerou transformações no modo como são organizadas as unidades curriculares em que cada um exerce a docência, bem como no papel atribuído aos estudantes universitários, quando focam transfor- 
mações ocorridas no exercício da docência, essa concentração recai no nível "médio" (31\%) e "muito" (31\%).

No que diz respeito ao modo como é assegurado o ensino-aprendizagem, a incidência das respostas situa-se no nível "médio" (44\%), seguida do "muito" (25\%) e "muitíssimo" (25\%), e no caso da avaliação, nos níveis "muito" (31\%), "médio" (25\%) e "muitíssimo" (25\%).

A situação de tensão é também patente quando se analisam as respostas aos aspectos referentes a transformações no exercício da investigação, nas atividades de extensão e na relação entre ensino-investigação-extensão. Nestes casos, há uma concentração na escala de $63 \%$ a $76 \%$, de respostas que apontam transformações no nível "pouco" ou "médio", e uma minoria na escala de $24 \%$ a 36\%, no nível "muito" e "muitíssimo". Estes valores permitem concluir que, para estes professores, o PB não gerou grandes efeitos ao nível do exercício destas dimensões da atividade docente.

Em síntese, e tal como é sistematizado na Tabela 1, pode afirmar-se que, segundo os professores entrevistados, o PB conduziu a transformações na missão atribuída à Universidade. Pode concluir-se também terem existido transformações assinaláveis ao nível da organização dos cursos universitários, do modo como são estruturadas as unidades curriculares, do modo como cada professor as planifica e do papel atribuído aos estudantes universitários. Apesar do reconhecimento destas transformações, os dados levam a inferir que nos aspectos mais operacionais, relativos ao modo como é exercida a docência no ensino universitário e como é assegurado o ensino-aprendizagem e avaliado o que é aprendido, as transformações geradas foram menores. O mesmo acontece relativamente ao exercício da investigação e às atividades de extensão e relação entre ensino-investigação-extensão, onde houve uma concentração na escala de "pouco" e "médio".

Nesse sentido, estes dados apontam para a necessidade de aprofundar reflexões sobre o hiato entre alterações previstas e ocorridas no âmbito do PB. Nomeadamente em termos de pensar a docência universitária, conforme afirma Barroso (2014), no contexto do resgate da Universidade como lugar de ensino, investigação, inovação e intervenção.

Os dados permitem ainda afirmar que, apesar dos professores considerarem que houve transformações decorrentes do ideário do PB, a sua concretização tem sido relativamente limitada. Principalmente quando se considera que existe um descompasso entre o previsto e o vivido. Este descompasso é confirmado pelos dados que se apresentam na Tabela 2, relativa ao grau de adesão dos professores às políticas que estão a ser vividas no Ensino Superior. 
TABELA 2 - GRAU DE ADESÃO DE PROFESSORES ÀS POLÍTICAS ATUAIS UNIVERSITÁRIAS

\begin{tabular}{lcccc}
\hline \multirow{2}{*}{ Transformações } & \multicolumn{3}{c}{ Nível } \\
\cline { 2 - 5 } & Pouco & Médio & Muito & Muitíssimo \\
\hline $\begin{array}{l}\text { a) Adesão ao paradigma de Bolonha } \\
\text { b) Organização dos cursos universitários }\end{array}$ & $6 \%(1)$ & $50 \%(8)$ & $25 \%(4)$ & $19 \%(3)$ \\
$\begin{array}{l}\text { decorrentes do Processo de Bolonha } \\
\text { c) Adesão ao princípio subjacente aos ECTS }\end{array}$ & $6 \%(1)$ & $31 \%(5)$ & $50 \%(8)$ & $12 \%(2)$ \\
$\begin{array}{l}\text { d) Adesão ao sistema de tutoria para as } \\
\text { aprendizagens }\end{array}$ & $19 \%(3)$ & $44 \%(7)$ & $50 \%(8)$ & $6 \%(1)$ \\
\hline
\end{tabular}

FONTE: As autoras (2015).

Uma análise da Tabela 2 permite verificar uma concentração de respostas na escala "muito", relativa a aspectos de adesão às políticas que implicaram alterações à organização dos cursos universitários, no âmbito do paradigma de Bolonha (50\%) e aos princípios subjacentes aos ECTS (50\%). Contrariando esta concentração de respostas, no caso da adesão ao paradigma veiculado pelo PB e ao sistema de tutoria para as aprendizagens, os resultados mais expressivos encontram-se na escala "médio". Ou seja, comparando os dados das respostas relativas ao grau de adesão às políticas decorrentes do PB com as transformações ocorridas, constata-se existir uma certa tensão, embora reconhecendo que alguns dos aspectos "impostos" possam ter tido efeitos positivos.

Analisando agora as respostas à "pergunta aberta" que referencia desafios que os professores consideram estar a enfrentar no exercício da docência, a análise de conteúdo (KRIPPENDORF, 2003) permitiu identificar alguns desses desafios. Nas respostas apresentadas, todos os aspectos enunciados relacionam-se com os processos de ensino, o papel que deverão ter os estudantes na aprendizagem e os procedimentos de avaliação das aprendizagens. É referido, por exemplo: "O maior desafio é conseguir pôr os estudantes a trabalharem efetivamente em grupo"; "lecionar grandes grupos"; "gerir o tempo"; "falta de formação em novas tecnologias". É também referida a "dificuldade no relacionamento com os alunos" e a dificuldade em "encontrar formas que ajudem os estudantes a ser autónomos". Tais desafios revelam, no âmbito das exigências de mudança que o PB implica, limitadas condições para as realizar, ou seja, apontam no sentido do que Vieira (2009, p. 116) afirma sobre este Processo: “[...] a par da actual retórica de mudança e dos esforços empreendidos para a inovação das práticas pedagógicas, e em desarticulação com essa retórica e esses esforços, opera, cada vez mais, uma lógica estreita de produtividade".

Nos desafios identificados pelos inquiridos, foi ainda realçado o novo papel que se espera dos estudantes e o que o PB pressupõe ao nível da avaliação da 
aprendizagem, nomeadamente corroborando o que é referido por Leite (2012) relativo ao despreparo dos professores e dos estudantes para interagirem no âmbito da sistemática relação entre um ensino-aprendizagem ancorada numa perspetiva crítica. Exemplos desta situação são as respostas que ilustram este despreparo: "é difícil aos estudantes perceberem que têm que cumprir um papel diferente"; "não se tem conseguido cumprir alguns pressupostos, como da avaliação formativa e formadora".

\section{Considerações finais}

Como neste texto foi referido, o $\mathrm{PB}$, no seu ideário, veiculou uma concepção de ensino que rompe com a visão tradicionalista que o restringe à mera transmissão e aquisição de conhecimentos. Ao contrário, aponta para a importância da aprendizagem e do desenvolvimento de competências pessoais e sociais fundadas em princípios de autonomia e de emancipação. Foi tendo por referência este discurso que foi realizado o estudo a que este artigo se refere e que teve como objetivo conhecer efeitos na docência universitária decorrentes do Processo de Bolonha.

A análise dos dados recolhidos permite afirmar que o $\mathrm{PB}$, no caso da U.Porto, e segundo opiniões de professores que representam distintas áreas do conhecimento e de experiência docente e com distintos lugares na carreira acadêmica, originou transformações na missão atribuída à Universidade, assim como na organização das unidades curriculares e no papel atribuído aos estudantes. Os dados permitem igualmente constatar que existe uma relação de interdependência entre a gestão institucional e a gestão curricular. Ou seja, o estudo realizado permite concluir que o PB gerou transformações que implicaram novas formas de conceber os cursos, o currículo e o seu desenvolvimento, e, por isso, novos modos de exercer a docência, nomeadamente na orientação dos processos de ensino, aprendizagem e avaliação.

No entanto, quando comparados esses efeitos, reconhecidos ao PB na gestão do currículo, com as condições que existem para operacionalizar o ideário que o suporta, são identificadas tensões. Os professores a que este estudo se refere, embora manifestem aderir aos princípios que apoiam modos de trabalho pedagógico (LESNE, 1984) docente orientados para a aprendizagem e o desenvolvimento da autonomia dos estudantes, expressam limites para a sua concretização. Esta tensão é evidente quando analisada a relação com os novos papéis que devem ser assumidos pelos estudantes e que justificam a contabilização do 
tempo de formação através de ECTS. Contrariando os princípios que suportam a organização dos cursos em função desta unidade de medida (ECTS), esta tensão é indicadora da distância que existe entre as alterações previstas e as ocorridas.

Como neste texto foi referido, o Ensino Superior de Portugal tem-se confrontado com lógicas de mercado e de uma cultura de produtividade, a par de exigências pedagógico-didáticas que implicam, da parte de professores, vontade, mas também disponibilidade de tempo, para um maior cuidado no acompanhamento dos estudantes na construção das suas aprendizagens. Ou seja, o sistema de Ensino Superior português, conforme Cabrito (2011, p. 22), “[...] encontra-se, pois, a viver uma situação de forte instabilidade e incerteza, que se repercute, perigosamente, na democraticidade e na equidade do sistema, na qualidade do ensino e na sua capacidade para a construção de uma sociedade mais justa e equitativa".

Um outro aspecto a reter nestas Considerações finais, e como foi expresso em outro estudo (LEITE; RAMOS, 2014), prende-se com a relação do ensino com a investigação e a extensão. A política em que se insere o $\mathrm{PB}$, embora aponte para a importância do recurso a processos de tutoria das aprendizagens que potenciam relações com a investigação, e desta com situações reais, não gerou os efeitos enunciados. Ou seja, os dados deste estudo corroboram o que é afirmado por Leite e Magalhães (2009):

[...] se a pedagogia implica um (auto)questionamento continuado sobre o que é um bom ensino e uma boa aprendizagem, então a sua indagação, tão crítica quanto possível, constitui um imperativo moral de todos os educadores. É nosso dever lutar por um futuro melhor para a pedagogia nas universidades, o que implica aprender a lidar com os paradoxos e dilemas da actividade académica, reconfigurando continuamente as nossas identidades profissionais. (LEITE; MAGALHÃES, 2009, p. 124).

Nesse sentido, é importante ressaltar a necessidade de ser dada atenção aos desafios que os docentes estão a enfrentar, diante das exigências colocadas pelo Processo de Bolonha e pela progressão na carreira. O que está a ocorrer obriga os professores universitários a confrontarem-se com dilemas gerados por um ideário que requer modos de trabalho pedagógico de orientação crítica (LEITE, 2002; PACHECO, 2014) e condições de trabalho que se guiam pelo que Ball (2004) designa por cultura da performatividade.

Esta constatação reclama, pois, uma atenção acrescida do Ensino Superior no sentido de, conforme Barroso (2014), resguardar os princípios da universidade 
pública em termos da diversidade, enquanto bem público, lugar de democracia, e de uma equidade com qualidade e autonomia. E esta atenção justifica-se, principalmente, se se pretende concretizar uma formação que, qualitativamente, intensifique a relação entre ensino-aprendizagem e pesquisa, e desta com situações de intervenção social. Este será um dos meios de tornar real a superação do paradigma tradicional, fundado no ensino transmissivo, concretizando, agora, o paradigma fundado na aprendizagem e no desenvolvimento pessoal, profissional e institucional.

\section{REFERÊNCIAS}

BALL, S. Performatividade, privatização e o pós-estado do bem-estar. Educação \& Sociedade, v. 25, n. 89, p. 1105-1126, set./dez. 2004.

BARROSO, J. Universidade pública: construir a universidade na diversidade. Conferência proferida no evento Dia da FPCEUP, 12 fev. 2014.

BECKER, H. Social-Class Variations in the Teacher-Pupil Relationship. Journal of Educational Sociology, v. 25, n. 8, p. 451-465, 1952.

BERNSTEIN, B. La estructura del discurso pedagógico. 3. ed. Madrid: Morata, 1997.

BIANCHETTI, L.; MACHADO, A. M. Publicar \& Morrer!? Análise do impacto das políticas de pesquisa e pós-graduação na constituição do tempo de trabalho dos investigadores. Educação, Sociedade \& Culturas, n. 28, p. 53-69, 2009.

CABRITO, B. Ensino superior em Portugal: incertezas e contradições. Revista Inter-Ação, v. 36, n. 1, p. 1-24, 2011.

DECLARAÇÃO DE BOLONHA. 1999. Disponível em: <http://www.ehea.info/Uploads/ Documents/1999_Bologna_Declaration_Portuguese.pdf $>$. Acesso em: 20 ago. 2013.

DELGADO, J. Neoliberalismo y capitalismo académico. 2007. Disponível em: $<$ http:// firgoa.usc.es/drupal/node/34777>. Acesso em: 12 fev. 2014.

FREIRE, P. Pedagogia da autonomia: saberes necessários à prática educativa. São Paulo: Paz e Terra, 1996.

GIBBONS, M. et al. The New Production of Knowledge: the dynamics of science and research in contemporary societies. London: Sage, 1998.

KRIPPENDORF, K. Content analysis: an introduction to its methodology. Londres: SAGE, 2003. 
LEITE, C. O currículo e o multiculturalismo no sistema educativo português. Lisboa: Fundação Calouste Gulbenkian, 2002.

LEITE, C. Qualidade da Educação Superior e formação de professores: Uma análise a partir da situação em Portugal. In: CUNHA, M. I.; BROILO, C. (Orgs.). Qualidade da Educação Superior: Grupos investigativos internacionais em diálogo. Araraquara: Junqueria \& Marin, 2012. p. 99-117.

LEITE, C.; FERNANDES, P. Inovação pedagógica: Uma resposta às demandas da sala de aula universitária. Perspectiva, v. 29, n. 2, p. 507-533, 2011.

LEITE, C.; MAGALHÃES, A. Prefácio ao dossiê temático "Políticas e desenvolvimento curricular no Ensino Superior". Educação, Sociedade \& Culturas, v. 28, p. 9-11, 2009.

LEITE, C.; RAMOS, K. Formação para a docência universitária: uma reflexão sobre o desafio de humanizar a cultura científica. Revista Portuguesa de Educação, Braga, v. 25, n. 1, p. 7-27, 2012.

LEITE, C.; RAMOS, K. Políticas do Ensino Superior em Portugal na fase pós-Bolonha: implicações no desenvolvimento do currículo e das exigências ao exercício docente, 2014. (submetido para publicação, doc. policopiado).

LESNE, M. Trabalho pedagógico e formação de adultos. Lisboa: Fundação Calouste Gulbenkian, 1984.

LIMA, L. Patterns of institutional management: democratisation, autonomy and the managerialist canon. In: NEAVE, G.; AMARAL, A. (Eds.). Higher education in Portugal 1974-2009: a nation, a generation. Porto/Londres: CIPES/Springer, 2012. p. 287-306.

LIMA, L.; AZEVEDO, M.; CATANI, A. O Processo de Bolonha, a avaliação da Educação Superior e algumas considerações sobre a Universidade Nova. Avaliação, v. 13, n. 1, p. 7-36, 2008.

MAGALHÃES, A. A identidade do ensino superior política, conhecimento e educação numa época de transição. Braga: Fundação Calouste Gulbenkian/Fundação para a Ciência e a Tecnologia/Ministério da Ciência e do Ensino Superior, 2004.

MAUÉS, O. A reconfiguração do trabalho docente na educação superior. Educar em Revista, n. especial 1, p. 141-160, 2010.

NÓVOA, A. Nada substitui o bom profesor. In: NÓVOA, A. Desafios do trabalho do profesor no mundo contemporâneo. São Paulo: Sinpro, 2007. Disponível em: <http:// www.sinprosp.org.br/arquivos/novoa/livreto_novoa.pdf>. Acesso em: 12 fev. 2014.

PACHECO, J. A. Educação, formação e conhecimento. Porto: Porto Editora, 2014.

PORTUGAL. Lei no 49/2005, de 30 de agosto de 2005. Diário da República, Lisboa. Disponível em: <https://dre.pt/application/file/245260>.

PORTUGAL. Decreto-Lei no 74/2006, de 24 de março de 2006. Diário da República, Lisboa. Disponível em: <https://dre.pt/application/file/671482>. 
ROBERTSON, S. O Processo de Bolonha da Europa torna-se global: modelo, mercado, mobilidade, força intelectual ou estratégia para a construção do Estado?. Revista Brasileira de Educação, v. 14, n. 42, p. 407-422, 2009.

ROBERTSON, S.; DALE, R. Regulação e risco na governação da educação: Gestão dos problemas de legitimação e coesão social em educação nos estados competitivos. Educação, Sociedade \& Culturas, n. 15, p. 117-147, 2001.

SANTOS, B. Um discurso sobre as ciências. 8. ed. Porto: Edições Afrontamento, 1996.

TARDIF, M.; LESSARD, C. O trabalho docente: elementos para uma teoria da docência como profissão de interações humanas. Petrópolis, RJ: Vozes, 2005.

UNESCO. Declaración Mundial sobre la Educación Superior en siglo XXI: visión y acción. 1998. Disponível em: $<$ http://www.unesco.org/education/educprog/wche/declaration_spa.htm>. Acesso em: 06 ago. 2006.

VALA, J. A Análise de conteúdo. In: SILVA, A.; PINTO, J. A. (Orgs.). Metodologia das Ciências Sociais. 3. ed. Porto: Edições Afrontamentos, 1989. p. 101-128.

VIEIRA, F. Em contracorrente: o valor da indagação da pedagogia na universidade. Educação, Sociedade \& Culturas, n. 28, p. 107-126, 2009.

Texto recebido em 07 de julho de 2015. Texto aprovado em 04 de agosto de 2015. 
